\title{
Anisotropy of the tensile properties in austenitic stainless steel obtained by wire-feed electron beam additive growth
}

\author{
E. V. Melnikov ${ }^{\dagger}$ E. G. Astafurova, S. V. Astafurov, G. G. Maier, V. A. Moskvina, \\ M. Yu. Panchenko, S. V. Fortuna, V.E. Rubtsov, E. A. Kolubaev \\ ${ }^{\dagger}$ melnickow-jenya@yandex.ru
}

Institute of Strength Physics and Materials Science SB RAS, 2/4 Akademichesky Av., Tomsk, 634055, Russia

\begin{abstract}
Currently, new approaches to the production of metal structures of different sizes are actively developing. These approaches are based on the technologies of additive manufacturing or 3D printing methods, which assume consistent layer-by-layer growth (printing) of parts of structures with a shape and size that are as close as possible to the desired parameters. During these processes, each subsequent layer is formed by fusing the material to preceding layers. Thus, the methods of additive growth are based on heating a part of the material to the melting temperature. Therefore, in the process of printing, the billets experience multiple heating and cooling cycles. As a result, different parts of the billets have different thermal histories and could possess different mechanical properties. In this paper, the anisotropy of the tensile mechanical properties of the billet of austenitic Fe-18Cr-9Ni-0.08C steel produced by wire-feed electron-beam printing was investigated. It was experimentally shown that, after additive growth, the samples of austenitic steel, which were cut from different parts of the steel billet and differently oriented with respect to the growth direction possessed significant anisotropy of mechanical properties under uniaxial tension: yield strength varies in the range from 250 to $310 \mathrm{MPa}$, and elongation to failure ranges from 48 to $65 \%$. According to microstructural analysis, this behavior is associated with heterogeneity of the elemental composition, macroscopic heterogeneity of the dendritic structure of ferrite in austenite (layering), heterogeneity of the phase composition and residual stresses in the steel billet obtained by the additive wire-feed growth.
\end{abstract}

Keywords: austenitic steel, additive technologies, electron-beam 3D printing, mechanical properties, uniaxial tension.

\section{Introduction}

Corrosion resistance, heat resistance, high ductility and good strength characteristics make austenitic stainless steels (SS) attractive for wide use as structural materials [1,2]. Parts made of austenitic stainless steels may have a complex shape with internal cavities and channels. Their conventional production assumes a considerable metal consumption and requires complex metalworking after casting. Electron beam threedimensional (3D) printing is an effective resource-saving technology for the additive manufacturing (AM) of metal products of a complex shape, which are close to the final size and require minimal post-build processing. Using additive technologies, parts are produced by feeding the deposited material (metal powder or wire) along a predetermined trajectory, its melting by a heat source (for example, an electron beam or laser) and solidifying the molten material, which fuses with the underlying layer [3-9].

A microstructure and, consequently, the mechanical properties of the products obtained by the methods of additive growth, are significantly influenced by the processing parameters, including the source power, the deposition scheme (the feed speed and the trajectory of the material and beam movement), etc. [3-6,10]. During the production procedure, different areas of the resulting product are subjected to a complex heat treatment (they have a different thermal history), since the material is heated and cooled during the deposition of each subsequent layer. Such complex thermal cycles could lead to anisotropy and heterogeneity of the microstructure and mechanical properties of the billets. Regarding austenitic SS obtained by different AM methods, the anisotropy of mechanical properties is described, for instance, for AISI 304, 304L, 316L steels in [11-15]. This could be associated not only with the heterogeneity of the formation of a grain structure and microstructure, but also with a change in the phase and elemental composition of the additively manufactured billets [11-15].

This paper is devoted to identifying the influence of macro- and microstructure, elemental and phase composition on the anisotropy of the mechanical properties of Fe-18Cr-9Ni-0.08C (wt.\%) steel obtained by wire-feed electron-beam printing.

\section{Methods and materials}

Using a laboratory machine for electron beam wirefeed 3D printing, a billet (wall) with linear dimensions of $100 \times 30 \times 5 \mathrm{~mm}$ was grown with Fe-18Cr-9Ni-0.08C (wt.\%) steel wire. A layer-by-layer deposition strategy was used (Fig. 1a). Thirty parallel layers were deposited during the building process. A massive sheet of high-carbon steel was used as a substrate. The plate was not cooled during the 
growth process. A steel wire with a diameter of $1 \mathrm{~mm}$ was used. The parameters of the growing process were as follows: accelerating voltage $-30 \mathrm{kV}$, beam current $-16.5 \mathrm{~mA}$, scanning frequency $-1 \mathrm{kHz}$, wire feed speed $-3.3 \mathrm{~mm} / \mathrm{s}$, beam speed $-0.65 \mathrm{~mm} / \mathrm{s}$, beam scan $-4 \times 4 \mathrm{~mm}$. The AM process was carried out in vacuum.

Flat proportional dumbbell-shaped specimens for mechanical tensile tests were cut out from the billet. The dimensions of the working part of the specimens were $12 \times 2.6 \times 1.5 \mathrm{~mm}$. The orientation of the specimens relative to the original billet is specified in Fig. $1 \mathrm{~b}$. The axes of uniaxial tension for specimens $2-5$ coincided with the direction of wire deposition (along the fusion layers and the beam movement). For specimens 1 and 6 , the tensile axes coincided with the building direction (across the layers). To compare the mechanical properties of additively grown specimens with cast material, coarsegrained specimens (with a grain size of $20 \mu \mathrm{m}$ ) of austenitic steel Fe-18Cr-9Ni-0.6Ti-0.08C (wt.\%) were prepared. Before testing, they were quenched from a temperature of $1100^{\circ} \mathrm{C}$ into cold water to obtain an austenitic structure (hereinafter mentioned as cast state).

Prior to mechanical testing, mechanical grinding and electrolytic polishing of the specimens in a solution of $25 \mathrm{gCrO}_{3}+210 \mathrm{ml} \mathrm{H}_{3} \mathrm{PO}_{4}$ was carried out. Uniaxial static tensile tests were performed at room temperature with an initial strain rate of $4.6 \times 10^{-4} \mathrm{~s}^{-1}$ using a LFM-125 testing machine (Walter + Bai AG). Microhardness according to the Vickers method was measured on the side surface of the billet along its building direction using a Duramin 5 microhardness tester. The load on the indenter was $200 \mathrm{~g}$.

The volume fraction of the ferrite phase in different parts of the billet was determined using a multifunction eddy-current instrument MVP-2M. The measurement step was $2 \mathrm{~mm}$.

The microstructure and elemental composition of the observed phases (energy dispersive X-ray spectral analysis, EDS) was studied using a Jeol JEM 2100 transmission electron microscope (TEM) at an accelerating voltage of $200 \mathrm{kV}$. Specimens were thinned to a thickness of $0.13 \div 0.15 \mathrm{~mm}$ by mechanical grinding, and then electrolytically polished in a solution of $95 \% \mathrm{CH}_{3} \mathrm{COOH}+5 \% \mathrm{H}_{3} \mathrm{ClO}_{4}$. For the TEM study, discs with a diameter of $3 \mathrm{~mm}$ each were cut from the bottom and top parts of the billet. The perforation regions (observations of the microstructure) were located at a distance of $\approx 2$ and $\approx 8 \mathrm{~mm}$ from the substrate.

The microstructure on the end surfaces of the billet was also inspected by light microscopy using an Altami MET 1C metallographic microscope. To reveal the microstructure, the polished surfaces of the specimens were subjected to electrochemical etching in a $10 \%$ aqueous solution of oxalic acid.

\section{Results and Discussion}

Fig. 2 shows the engineering stress-elongation diagrams for the SS specimens depending on their orientation relative to the growth direction and position in the billet obtained by the AM method. The diagrams for additively grown specimens have a form typical for coarse-grained cast austenitic steels, but their mechanical properties are lower (Fig. 2).
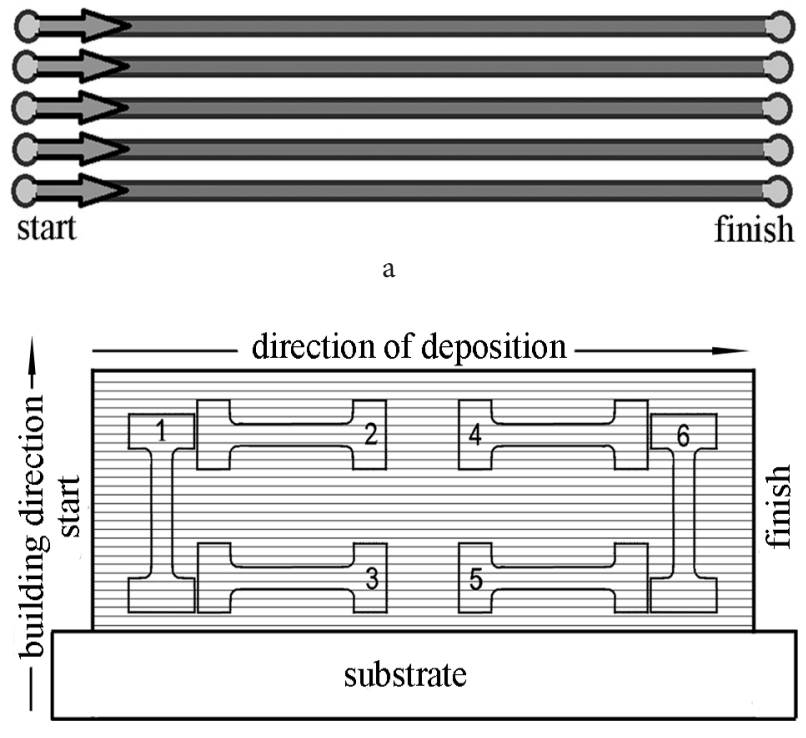

b

Fig. 1. Scheme of deposition of layers during wire-feed electron beam $3 \mathrm{D}$ printing (a) and scheme of orientation of tensile samples relative to the initial bulk material (b).

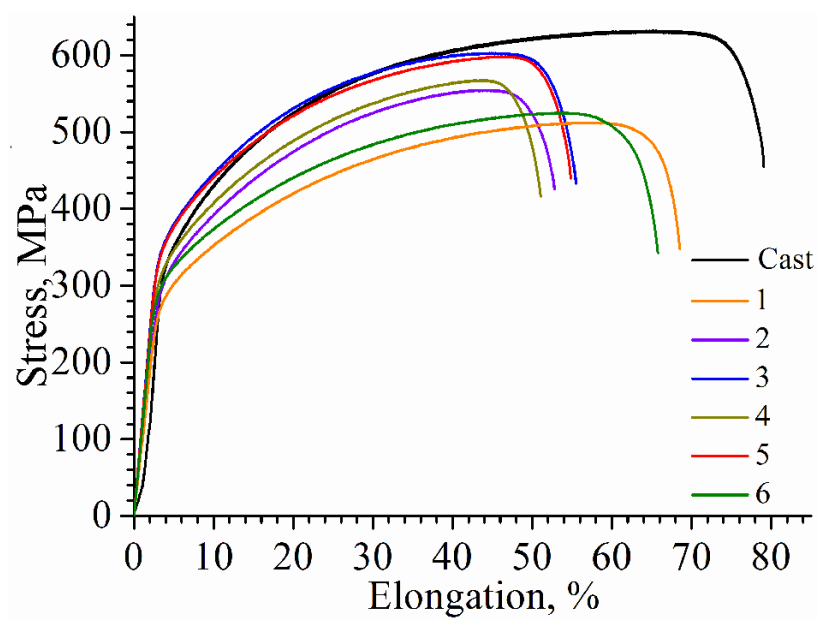

Fig. 2. (Color online) Engineering stress-elongation diagrams for austenitic steel specimens produced by additive manufacturing. Sample numbering (1-6) follows the pattern in Fig. 1b. Cast-tensile diagram for coarse-grained specimens of cast steel Fe-18Cr-9Ni-0.6Ti-0.08C (wt.\%).

Depending on the orientation of the specimens with respect to the direction of deposition of the wire, the values of the mechanical properties vary within a wide range: the yield strength $\left(\sigma_{0.2}\right)$ varies from 250 to $310 \mathrm{MPa}$, and the total elongation to failure $(\delta)$ ranges from 48 to $65 \%$ (Fig. 2). Specimens 1 and 6 , for which the tensile axis coincides with the building direction, have lower values of yield strength and ultimate tensile strength and higher elongation in comparison with samples 2-5, which were cut in the direction of deposition of the wire. Specimens 2 and 4, corresponded to the upper part of the wall, have lower values of both strength characteristics and elongation as compared to specimens 3 and 5, which were cut from the lower part of the billet (near the substrate). That is, the steel billet after electronbeam wire-feed 3D printing has significant anisotropy of mechanical properties. 
Fig. $3 \mathrm{a}, \mathrm{b}$ show microhardness distributions in steel specimens depending on the distance from the substrate. These data confirm the tensile test results on the anisotropy of the strength properties. The microhardness values are higher, and their dispersion is larger in the region next to the onset of the wall growth. Then the microhardness decreases and reaches a "plateau" at a distance of $6 \div 8 \mathrm{~mm}$ from the substrate (Fig. 3a,b).

The distribution of the volume fraction of the magnetic $\delta$-phase in the billet depending on the distance to the substrate is shown in Fig. 3 a,b. The maximum content of $\delta$-ferrite is characteristic of the transition zone between the deposited SS and the ferromagnetic high-carbon steel substrate. At a distance of $2 \mathrm{~mm}$ from the substrate, the content of the magnetic $\delta$-phase sharply decreases, and then it characterizes the volume fraction of ferrite in the investigated SS (the working parts of the tensile specimens (3) and (5) correspond to this region). The volume content of ferrite increases in the range of $20 \div 27 \%$, as the distance to the substrate increases in the range of $2 \div 28 \mathrm{~mm}$. It has higher values in that part of the wall where the growth of each layer was completed. That is, with an increase in the heating temperature of the billet, a large portion of ferrite in the steel structure is formed (Fig. $3 \mathrm{a}, \mathrm{b}$ ). The formation of high-temperature ferrite in austenitic SS during the AM process was noted in many studies [11-14,16,17], including those for stable AISI 316L steel $[14,8]$, in which the nickel content in the initial material is higher than in the investigated steel (12\% versus 9\%).

Images of the structure of the billet obtained by light microscopy are shown in Fig. $3 \mathrm{c}$, d. Macroscopically, the structure is a sequence of layers with different etchability. That is, a macroscopically heterogeneous layered material is

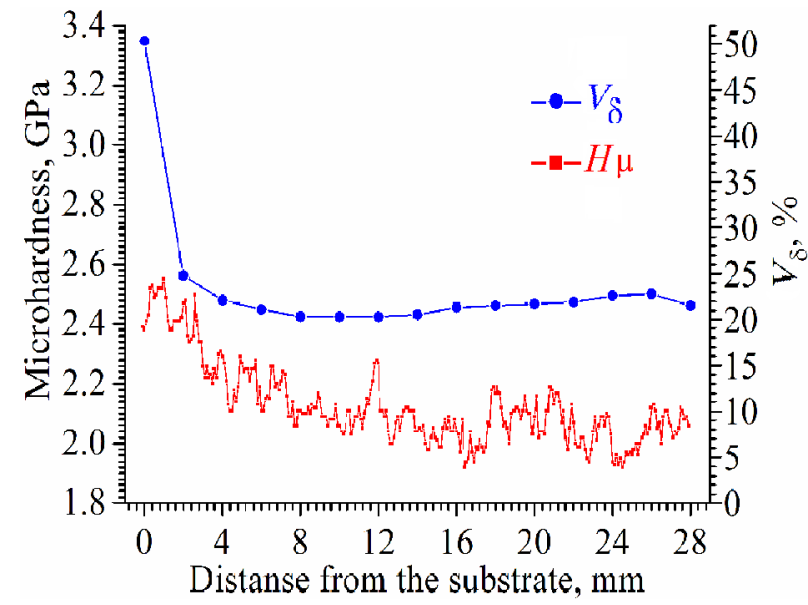

a

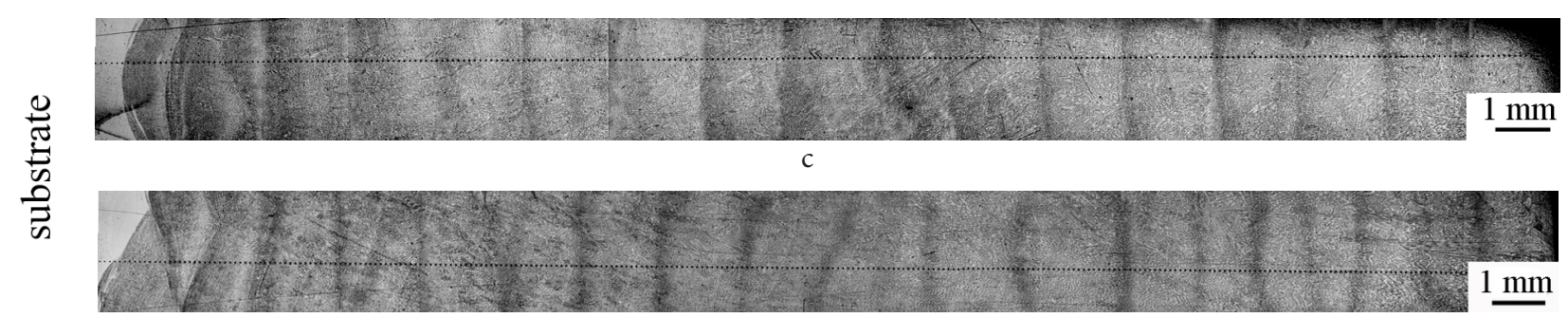

d

Fig. 3. (Color online) The distribution of microhardness and volume fraction of ferrite in dependence on the distance from the substrate (a, b). Images of the microstructure of the billet obtained by light microscopy (c, d): "start" (a, c); "finish" (b, d). formed during AM. The lighter areas (with low etchability) correspond to the inner part of the wire, and the darker ones (with increased etchability) - to the zones of fusion of the layers between themselves. Such macroscopic inhomogeneities (boundaries of fused layers) can affect the mechanical properties of additively grown parts [18].

After the AM, steel billets possess a two-phase $\gamma+\delta$ $(\mathrm{fcc}+\mathrm{bcc})$ microstructure (Fig. 4), which is formed during melting of the wire under the influence of an electron beam and subsequent crystallization. The microstructure of the fused metal is characterized mainly by the dendritic structure, but individual spherical ferrite grains are also observed (Fig. 5). The volume content of ferrite, as determined by the analysis of metallographic images, is lower than that determined by the magnetophase analysis method (Fig. 3), and varies in the range of $10-17 \%$. Such quantitative differences in the volume content of $\delta$-ferrite obtained by different methods can be associated with their inhomogeneous distribution in the billet. This fact requires additional research using other methods of phase analysis.

TEM studies of the microstructure of the specimens did not reveal any obvious differences in the morphology of ferrite and austenite depending on the position of the observation area in the billet (Fig. $4 \mathrm{a}, \mathrm{b}$ ). The branches of dendrites have a transverse size less than $1 \mu \mathrm{m}$ (rarely up to $2 \mu \mathrm{m}$ ) both in upper and lower parts of the billet. In the specimens cut near the substrate, a large number of narrow extinction contours in the ferritic and austenitic regions were observed in TEM images. In the upper layers of the billet, the contours were either wide, or they were not observed at all. This indirectly indicates higher microstresses in the crystal lattice in the lower layers of the AM wall.

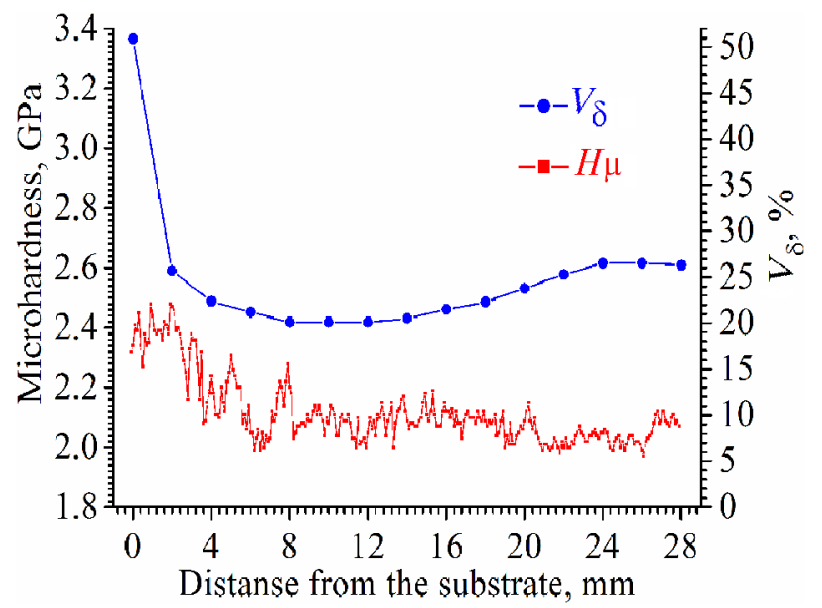

b $\mathrm{mm}$ 


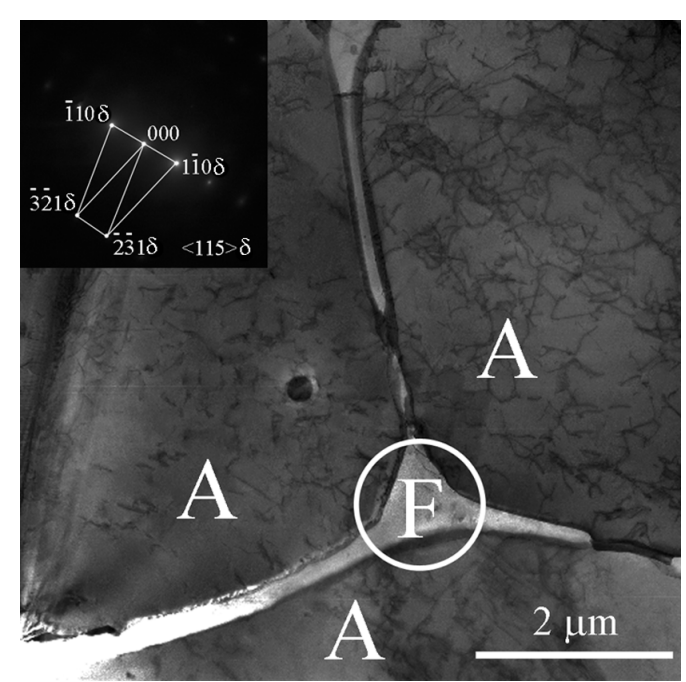

a

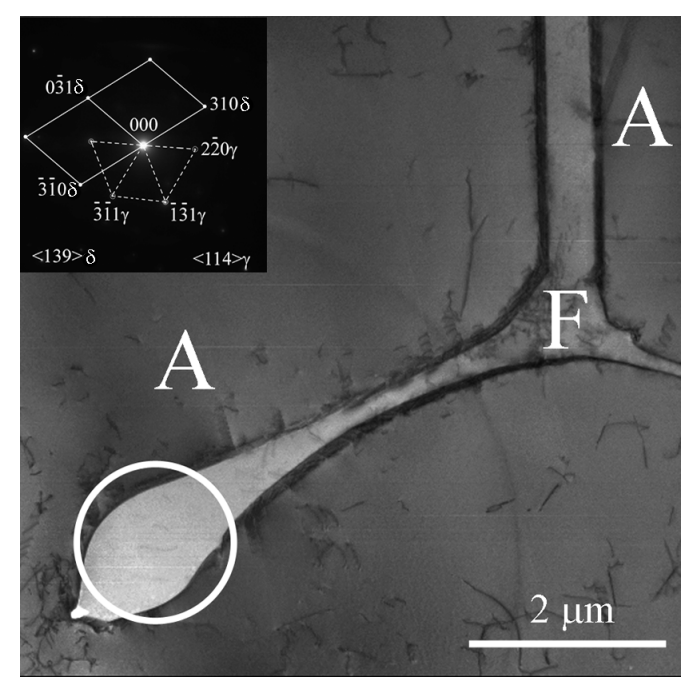

b

Fig. 4. TEM-images of the microstructure of Fe-18Cr-9Ni-0.08C steel in the lower (a) and upper (b) parts of the billet obtained by the method of additive wire-feed growth. Fig. (a) and (b) correspond to the distances $\approx 2 \mathrm{~mm}$ and $\approx 28 \mathrm{~mm}$ from the substrate. Selected area diffraction patters were obtained from the areas shown by circles in TEM images. $\mathrm{A}-$ austenite, $\mathrm{F}-\delta$-ferrite.

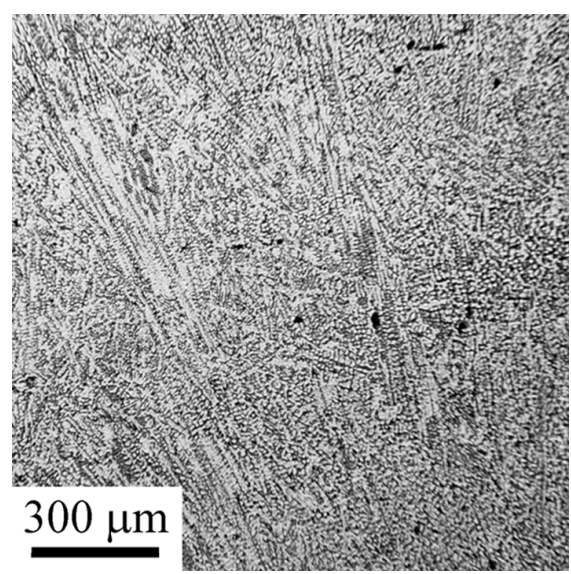

a

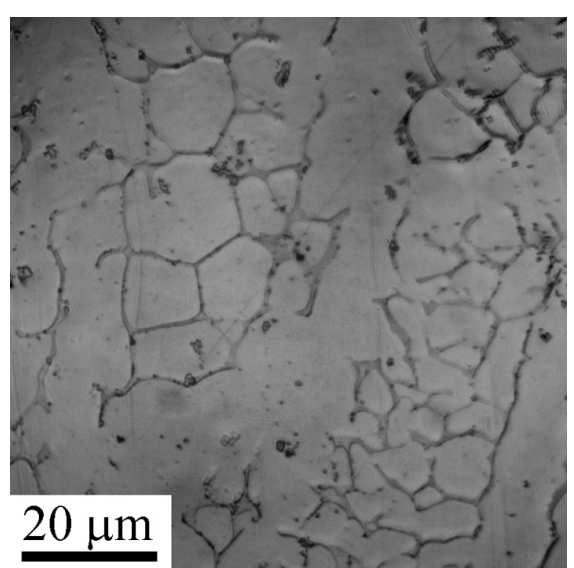

$\mathrm{b}$

Fig. 5. Images of the microstructure in Fe-18Cr-9Ni-0.08C steel in middle part of the billet obtained by the method of additive wire-feed growth.

Independently on the distance to the substrate, TEM studies revealed a planar dislocation structure in austenite, which is characteristic of austenitic steels (Fig. 4a,b). The ferrite and austenitic grains contain dislocations of not very high density (of the order of $10^{12} \mathrm{~m}^{-2}$ ): the scalar dislocation densities are $3 \times 10^{12} \mathrm{~m}^{-2}$ in the lower part and $1 \times 10^{12} \mathrm{~m}^{-2}$ in the upper part of the billet. Locally, regions with a higher dislocation density up to $3 \times 10^{12} \mathrm{~m}^{-2}$ are observed. The experimentally measured values of the dislocation density lie on the lower boundary of the range of values typical for additively grown steels $\left(10^{12} \div 10^{14} \mathrm{~m}^{-2}\right)$ [19]. R. Pokharel et al. [20] showed that for additively grown specimens of AISI 304L steel, the broadening of diffraction lines (which could indicate the presence of microstresses) was caused by the accumulation of excess density of slip dislocations and can be eliminated by post-grown heat treatments. Using TEM EDS analysis, the elemental composition of the phases in different parts of the billet was determined (Table 1). The ferrite regions are enriched with chromium and depleted of nickel relative to the austenitic phase. It is important to note that the concentration of nickel in austenite is reduced in the upper part of the billet relative to the lower one (near the substrate). This indicates that nickel loss occurs in the AM process due to heating of the wall. Since chromium is a ferrite-forming element, and nickel stabilizes the austenitic phase, this factor can contribute to an increase in the volume content of ferrite with increasing distance from the substrate (along with a decrease in the cooling rate during crystallization).

A change in the volume content of ferrite was previously noted in [12] for the AM billet in the form of a ring made of AISI 304-type austenitic steel. The authors established that the residual stresses at the bottom of the billet were 1.4 times higher than in the upper part (with a ring height of $\approx 15 \mathrm{~mm}$ ). These results confirm the TEM data on the differences in the value of residual stresses in the upper and lower parts of the billet. Z. Wang et al. [13] also noted that in AISI 304L steel specimens obtained by direct laser deposition, the lower part of the billet has a higher tensile strength due to the greater dispersion of the microstructure compared to the 
Table 1. Elemental composition of ferritic and austenitic phases in different parts of the as-built billet (wt.\%, Fe — balanced).

\begin{tabular}{|c|c|c|c|c|c|c|}
\hline Position in the billet & Phase & $\mathrm{Cr}$ & $\mathrm{Ni}$ & $\mathrm{Mn}$ & $\mathrm{Si}$ & $\mathrm{Cu}$ \\
\hline \multirow{2}{*}{ Bottom (2 mm next to the substrate) } & $\gamma$ & 20.9 & 10.1 & 0.8 & 1.2 & 0.9 \\
\cline { 2 - 7 } & $\delta$ & 29.5 & 4.2 & 0.2 & 2.0 & 0.7 \\
\hline \multirow{2}{*}{ Top (28 mm next to the substrate) } & $\gamma$ & 21.4 & 8.7 & 0.9 & 1.4 & 1.0 \\
\cline { 2 - 7 } & $\delta$ & 28.7 & 4.3 & 0.8 & 1.7 & 0.9 \\
\hline
\end{tabular}

upper part. The dependences of the mechanical properties on the orientation of the tensile axis with respect to the direction of growth of the layers reported by Z. Wang et al. in [13] were similar to the regularities found in this study. The authors explained a similar anisotropy of plastic properties in an AISI 304L steel billet in terms of the mean free path of dislocations in austenitic grains, which is satisfactorily described by the Hall-Petch relationship.

Thus, the increase in the microhardness and strength properties of steel during tension of specimens cut near the substrate relative to the upper part of the billet could be assisted by several reasons: differences in the microstructure and phase composition in different parts of the wall and the heterogeneity of the chemical composition of the billet after growth. The formation of a two-phase $(\gamma+\delta)$ structure in the process of additive production is accompanied by a decrease in the strength and plastic properties of austenitic steel in comparison with the cast analog.

\section{Conclusion}

Using the method of wire-feed electron-beam printing, the billet (wall) of austenitic stainless Fe-18Cr-9Ni-0.08C (wt.\%) steel was produced. It was experimentally established that after the additive growth, specimens cut from different parts of the billet and oriented differently with respect to the direction of additive growth have different mechanical properties under uniaxial tension. Based on microstructural studies, it was established that the anisotropy of the mechanical characteristics is associated with heterogeneity of the elemental composition, macroscopic heterogeneity of the dendritic structure of ferrite in austenite (layering), heterogeneity of the phase composition and residual stresses in the billet obtained by the additive wirefeed growth.

Acknowledgements. This work was performed within the frame of the Fundamental Research Program of the State Academies of Sciences for 2013-2020, line of research III.23.2.7. The study was conducted using the equipment of Institute of Strength Physics and Materials Science (NANOTECH center).

\section{References}

1. K. H. Lo, C. H. Shek, J. K. L. Lai. Mater. Sci. and Eng.: R. 65 (4-6), 39 (2009). Crossref

2. H.K.D.H. Bhadeshia, R. Honeycombe. Elsevier Ltd., Oxford, UK (2006) 344 p.
3. D. Ding, Z. Pan, D. Cuiuri, H. Li. Int. J. Adv. Manuf. Technol. 81, 465 (2015). Crossref

4. J. Fuchs, C. Schneider, N. Enzinger. Weld World. 62, 267 (2018). Crossref

5. T. DebRoy, H.L. Wei, J.S. Zuback, T. Mukherjee, J. W. Elmer, J. O. Milewski, A. M. Beese, A. Wilson-Heid, A. De, W. Zhang. Progress in Mater. Sci. 92, 112 (2018). Crossref

6. D. Herzog, V. Seyda, E. Wycisk, C. Emmelmann. Acta Mater. 117, 371 (2016). Crossref

7. L.E. Murr, S.M. Gaytan, D.A. Ramirez, E. Martinez, J. Hernandez, K.N. Amato, P.W. Shindo, F.R. Medina, R. B. Wicker. J. Mater. Sci. Technol. 28 (1), 1 (2012). $\underline{\text { Crossref }}$

8. L. Wang, S.D. Felicelli, J. Coleman, R. Johnson, K. M. B. Taminger, R. L. Lett. Proceedings of the ASME 2011 International Mechanical Engineering Congress \& Exposition, IMECE2011. Denver, Colorado, USA (2011) p.15. $\underline{\text { Crossref }}$

9. T. Skiba, B. Baufeld, O. V. der Biest. J. Eng. Manuf. 225 (6), 831 (2011). Crossref

10. E. Liverani, S. Toschi, L. Ceschini, A. Fortunato. J. Mater. Process. Tech. 249, 255 (2017). Crossref

11. S. Yu. Tarasov, A.V. Filippov, N.L. Savchenko, S. V. Fortuna, V.E. Rubtsov, E. A. Kolubaev, S. G. Psakhie. Int. J. Adv. Manuf. Technol. 99, 2353 (2018). Crossref

12. A.V. Kolubaev, S.Yu. Tarasov, A.V. Filippov, Yu. A. Denisova, E. A. Kolubaev, A.I. Potekaev. Russ. Phys. J. 61, 1491 (2018). Crossref

13. Z. Wang, T. A. Palmer, A. M. Beese. Acta Mater. 110, 226 (2016). $\underline{\text { Crossref }}$

14. X. Chen, J. Li, X. Cheng, B. He, H. Wang, Z. Huang. Mater. Sci. and Eng.: A. 703, 567 (2017). Crossref

15. K. Guan, Z. Wang, M. Gao, X. Li, X. Zeng. Materials \& Design. 50, 581 (2013). Crossref

16. B. M. Morrow, T.J. Lienert, C.M. Knapp, J.O. Sutton, M. J. Brand, R. M. Pacheco, V. Livescu, J.S. Carpenter, G. T. Gray III. Metall. and Mat. Trans. A. 49, 3637 (2018). Crossref

17. P. Wanjara, M. Brochu, M. Jahazi. Mater. \& Design. 28 (8), 2278 (2007). Crossref

18. W. Shifeng, L. Shuai, W. Qingsong, C. Yana, Z. Sheng, S. Yusheng. J. Mater. Process. Tech. 214 (11), 2660 (2014). Crossref

19. J.S. Zuback, T. DebRoy. Materials. 11, 2070 (2018). Crossref

20. R. Pokharel, L. Balogh, D. W. Brown, B. Clausen, G. T. Gray III, V. Livescu, S.C. Vogel, S. Takajo. Scripta Mater. 155, 16 (2018). $\underline{\text { Crossref }}$ 